\title{
Variasi Komposisi Dan Kerapatan Jenis Lamun Di Perairan Ujung Piring, Kabupaten Jepara
}

\section{Retno Hartati', Widianingsih', Adi Santoso', Hadi Endrawati', Muhammad Zainuri2, Ita Riniatsih', W.L. Saputra' dan Robertus Triaji Mahendrajaya'}

\author{
'Departemen IImu Kelautan, Fakultas Perikanan dan IImu Kelautan, Universitas Diponegoro \\ 2Departemen Oseanografi, Fakultas Perikanan dan Ilmu Kelautan, Universitas Diponegoro \\ JI. Prof. Soedarto, SH. Kampus UNDIP Tembalang, Semarang 50275 \\ Email : retnohartati.undip@yahoo.com
}

\begin{abstract}
Seagrass has an important role for marine environment as a primary producer also as constituent and ecosystems habitats that support the life on coral reefs and mangrove or coastal. This research is aimed to identify the seagrass species and to undertand thier density and coverage. This research was conducted on June-August 2016 at Ujung Piring waters, Jepara. The research used descriptive method. Sampling was conducted on five stations, where each station performed five repetitions. The seagrasses found in research sites were identified and counted for their density and coverage. Seawater quality parameter were measured in situ. Sediment were take for grain size analysis to undertand their characteristic. The research showed that during the study period there were four species of seagrasses i.e. Enhalus acoroides, Thalasia hemprichii, Cymodocea Rotundata, and Syringodium isoetifolium. Overall this study indicate the highest and lowest density found in Thalassia hemprichii $\quad 33,87$ and 4,35 stands $\left./ \mathrm{m}^{2}\right)$. E. acoroides had highest coverage $(48,67 \%)$ while the lowest $(8,71 \%)$ was T. hemprichii. There were variation in density and covarage of seagrass species due to water quality and showed uneven distribution of the seagrass species in that area.
\end{abstract}

Keywords : Enhalus acoroides, Thalasia hemprichii, Cymodocea rotundata, dan Syringodium isoetifolium, variasi komposisi,

\begin{abstract}
Abstrak
Lamun memiliki peranan penting bagi kehidupan di laut sebagai produsen primer serta penyusun habitat dan ekosistem yang menyangga kehidupan di terumbu karang dan mangrove atau daratan pantai. Penelitian ini bertujuan untuk mengidentifikasi jenis-jenis lamun dan variasi kerapatan dan penutupannya di perairan Ujung Piring, Kabupaten Jepara. Penelitian ini dilakukan pada bulan Juni-Agustus 2016 di perairan Ujung Piring Jepara. Metode yang digunakan dalam penelitian ini adalah metode deskriptif. Pengambilan sampel dilakukan pada lima stasiun, dimana setiap stasiun dilakukan lima kali pengulangan. Lamun diidentifikasi di lokasi penelitian, dihitung kerapatannya dan penutupannya. Pengukuran kualitas perairan dilakukan in situ, sedangkan sedimen diambil untuk dianalisa butiran untuk mengetahui karakteristik sedimennya. Hasil penelitian ini menunjukkan selama periode penelitian terdapat 4 jenis Iamun, yaitu Enhalus acoroides, Thalasia hemprichii, Cymodocea rotundata, dan Syringodium isoetifolium. Kerapatan tertinggi dan terendah ditemukan pada Thalassia hemprichii yaitu 33,87 dan 4,35 tegakan $/ \mathrm{m}^{2}$. Persentase penutupan tertinggi ditemukan pada $E$. acoroides dengan nilai $48,67 \%$ dan yang terendah $8,71 \%$ oleh $T$. hemprichii. Terdapat variasi komposisi dan kerapatan berdasarkan waktu pengamatan, hal ini menunjukkan adanya pengaruh lingkungan dan tidak terjadi persebaran lamun yang merata pada daerah tersebut.
\end{abstract}

Kata Kunci : Enhalus acoroides, Thalasia hemprichii, Cymodocea rotundata, dan Syringodium isoetifolium, variasi komposisi. 



\section{PENDAHULUAN}

Jepara sebagai salah satu kabupaten di Jawa Tengah terletak pada $05^{\circ} 43^{\prime} 20,67^{\prime \prime}$ sampai $06^{\circ} 47^{\prime} 25,83^{\prime \prime}$ Lintang

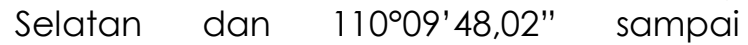
110 58'37,40" Bujur Timur. Kabupaten Jepara berada di bagian utara Pulau Jawa dan berbatasan langsung dengan Laut Jawa. Kabupaten Jepara terdiri dari wilayah daratan utama dan wilayah kepulauan. Pantai Ujung Piring terletak di Kecamatan Mlonggo, Kabupaten Jepara, tepatnya di Desa Sekuro. Pantai Ujung Piring merupakan salah satu pesisir yang masih sangat jarang dikunjungi oleh wisatawan. Pantai ini terletak di antara tiga desa yaitu Jambu, Blebak dan Sekuro. Pantai Ujung Piring berbentuk seperti teluk. Kawasan ini sebenarnya lebih banyak rawa dan tambak, serta banyaknya vegetasi mangrove yang berfungsi untuk menghindari abrasi air laut. Kawasan ini mayoritas sebagai tempat mata pencaharian nelayan lokal. Di Pantai Ujung Piring terdapat hamparan lamun yang cukup luas yang menjadi salah satu ekosistem yang penting di perairan tersebut. Selain sebagai produsen primer, padang lamun juga di gunakan sebagai tempat berlindung ikan.

Lamun memiliki peranan penting bagi kehidupan di laut, sebagai produsen primer serta penyusun habitat dan ekosistem yang menyangga kehidupan bagi ekosistem sekitarnya. Padang lamun merupakan tempat berlindung, mencari makan, dan tempat memijah bagi invertebrata kecil dan ikan. Sistem perakaran rhizome lamun dapat menstabilkan sedimen dan daun lamun dapat mengurangi kecepatan arus (Hogarth, 2007). Ekosistem padang lamun merupakan habitat penting bagi kelhidupan biota laut yang berasosiasi, bahkan menjadi penyokong alternatif mata pencaharian komunitas peisir. Padang lamun merupakan salah satu perairan laut yang paling produkstif dan penting (Thangaradjon et al., 2007). Selain sebagai perangkap sedimen, memperlambat arus pantai, menyokong produksi perikanan, sebagai habitat berbagai jenis biota laut. Namun ekosistem lamun sangat peka terhadap perubahan lingkungan serta berbagai perubahan lingkungan sebagai dampak kegiatan manusia, misalkan reklamasi pantai, pembangunan pelabuhan, pemukiman (Duarte, 2002), serta perngaruh perubahan lingkungan (Seddon et al., 2000).

Terdapat 13 jenis lamun yang termasuk dalam 7 famili dan 7 genera diantaranya hidup di perairan tropis yaitu Enhalus, Thalassia, Thalassodendron, Halophila, Halodule, Cymodocea, dan Syringodium (Kuriandewa 2009).. Komunitas padang lamun mempunyai 3 tipe vegetasi, yaitu monospesifik (tunggal), asosiasi dua/tiga jenis dan vegetasi campuran. Vegetasi monospesifik merupakan komunitas lamun yng terdiri atas satu jenis, dan terjadi sementara sebagai fase intermediate menuju situasi yang lebih stabil (vegetasi campuran). Vegetasi campuran biasannya terdiri dari beberapa asosiasi minimal 4 jenis.

Pertumbuhan dan distribusi lamun diatur oleh sifat-sifat fisik, kimia dan biologis lingkungan dimana lamun tumbuh. Cahaya yang cukup, nutrien dan karbon anorganik adalah kebutuhan dasar lamun untuk berfotosintesa, tetapi substrat yang layak, suhu, dedah udara saat surut serta beraneka faktor biologi mempengaruhi distribusinya. Interaksi bermacam faktor tersebut susah untuk dipisahkan sebagai satu faktor tunggal yang berpengaruh demikian juga untuk memprediksi adanya atau distribusi lamun pada tempat dan waktu tertentu. Namun demikian beberapa faktor yang paling berpengaruh terhadap pertumbuhan dan distribusi lamun dapat diidentifikasi. Selain persyaratak fisikan dan kimia untuk tumbuh, kompetisi dengan species lain juga berpengaruh terhadap pertumbuhan dan distribusi lamun. Berdasarkan uraian diatas, maka perlu dilakukan penelitian mengenai kondisi penutupan lamun di Pantai Ujung Piring, Jepara. Penelitian ini bertujuan untuk mengidentifikasi jenis-jenis lamun dan menghitung kerapatan dan penutupannya berdasarkan waktu dan lokasi penelitian

\section{MATERI DAN METODE}

Materi yang digunakan dalam penelitian ini adalah lamun sedimen dan 
air laut yang diambil di perairan Ujung Piring. Metode yang digunakan dalam penelitian ini adalah metode deskriptif, yaitu suatu metode dalam penelitian yang bertujuan membuat pencandraan secara sistematis, faktual dan akurat terhadap kejadian populasi tertentu pada suatu wilayah tertentu (Suryabrata, 1992).

Penentuan lokasi sampling dilakukan berdasarkan metode purposive sampling, yaitu penentuan lokasi sampling dengan pertimbangan tertentu oleh peneliti (Sudjana, 1996). Lokasi penelitian berada pada pantai Ujung Piring dengan 5 stasiun. Setiap stasiun di lakukan 5 pengulangan. Pengambilan sampel pada 5 stasiun yang berbeda bertujuan untuk membandingkan pola penyebaran spesies lamun pada keseluruhan stasiun. Pertimbangan penentuan lokasi stasiun penelitian. Peta lokasi penelitian tersaji dalam Gambar 1.

Pendataan lamun dilakukan dalam transek kuadran $1 \times 1 \mathrm{~m}^{2}$ dengan mengidentifikasi jenis lamun dan menghitung jumlah tegakan dari setiap kolom untuk mengetahui kerapatan dan menghitung penutupan lamun. Pengambilan sampel sedimen dilakukan dengan menggunakan sedimen core. Sedimen yang telah terambil dimasukkan ke dalam kantong plastik berlabel dan di dalam laboratorium dilakukan analisa grain sizenya. Parameter kualitas perairan diukur secara langsung, yaitu $\mathrm{pH}$, suhu, salinitas, kecerahan, kedalaman, dan arus.

Penghitungan kerapatan populasi lamun yang ada di perairan Ujung Piring, Jepara digunakan rumus (Azkab, 1999). Penghitungan persen penutupan lamun dapat dilakukan dengan cara memasukkan hasil data penghitungan tegakan dari setiap kolom transek kuadran dengan menggunakan rumus English et al. (1994).

Penentuan status padang lamun menurut Keputusan MNLH, No. 200/2004 dengan penutupan $\geq 60,30-59,9, \leq 29,9$ termasuk kategori kaya/sehat, kurang kaya/kurang sehat dan miskin.
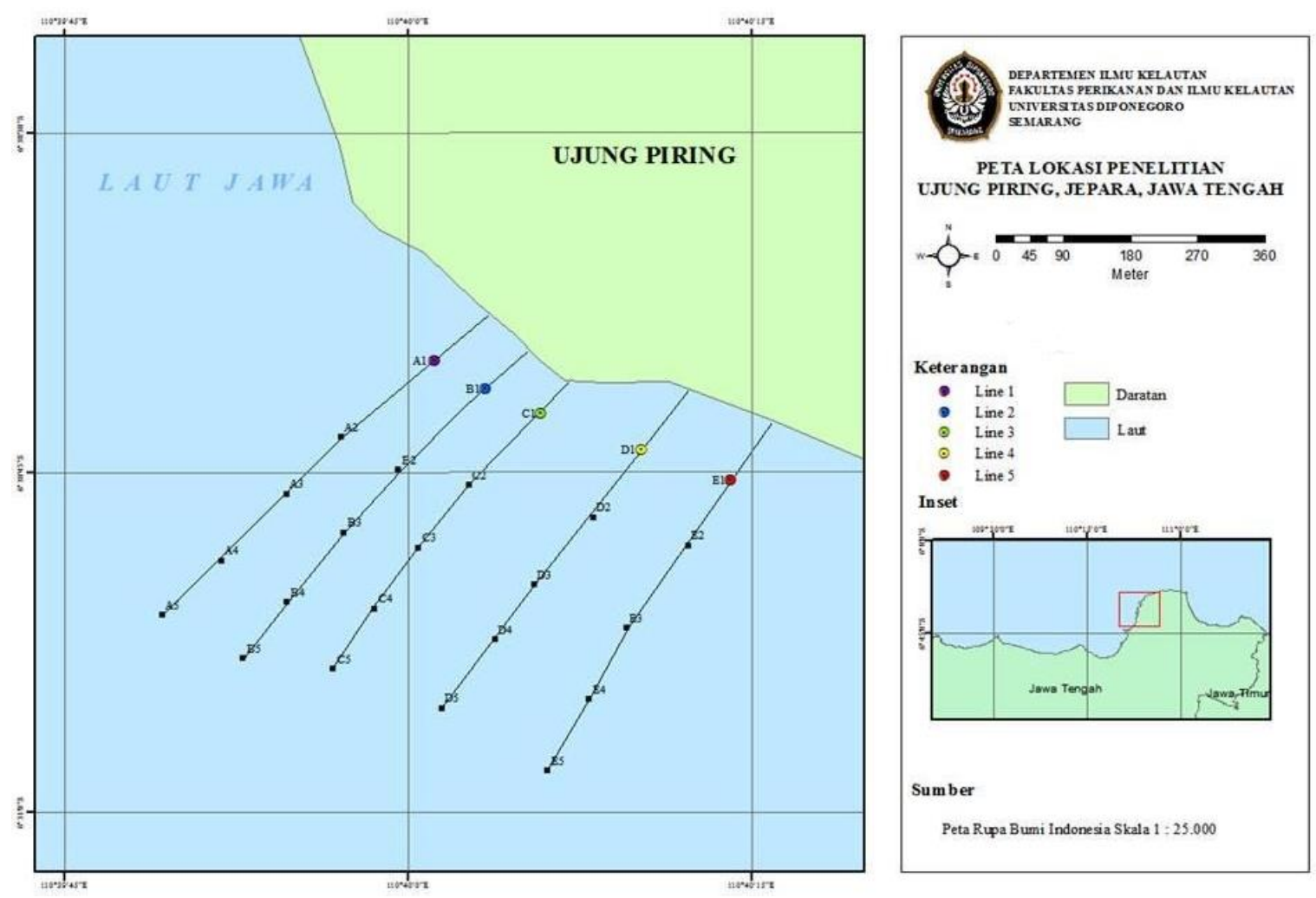

Gambar 1. Stasiun pengamatan lamun di perairan Ujung Piring, Jepara 


\section{HASIL DAN PEMBAHASAN}

\section{Komposisi Jenis Lamun}

Jenis Lamun yang di temukan selama penelitian di Pantai Ujung Piring Jepara sebanyak 4 spesies dari 2 famili. Famili Hydrocharitaceae ditemukan 2 spesies, yaitu Enhalus acoroides dan Thalasia hemprichii, sedangkan dari familiy Potamogetonaceae ditemukan 2 spesies, yaitu Cymodocea rotundata dan Syringodium isoetifolium (Gambar 2). E. acoroides memiliki daun yang berbentuk seperti pita dengan panjang daun $200 \mathrm{~cm}$ dan lebar hampir $2 \mathrm{~cm}$. Jenis rimpangnya tebal sampai $1 \mathrm{~cm}$ dan akarnya keras dan tebal dengan ukuran 0,3-0,5 cm. T. hemprichii memiliki panjang daun hingga $40 \mathrm{~cm}$ namun biasanya lebih pendek, sedangkan lebarnya yaitu 0,4-1 cm. Batangnya pendek dan tegak dengan jumlah daun yaitu 2-6 helai. Rimpangnya tebal dan ditutupi dengan daun. $C$. rotundata adalah jenis lamun yang hidup di perairan dangkal. Panjang helai daun $C$. rotundata berkisar $7-15 \mathrm{~cm}$, dan lebar daun $0,2-0,4 \mathrm{~cm}$. Rimpangnya halus, dan memiliki 1-3 akar bercabang yang tidak teratur pada setiap ruas (El Shaffai, 2011). S. isoetifolium adalah satu-satunya spesies dengan memiliki daun berbentuk silindris dan salah satu jenis yang paling mudah untuk di identifikasi. Panjang daun hingga $30 \mathrm{~cm}$ dan lebar $0,1-0,2 \mathrm{~cm}$, rimpangnya halus dan memiliki 1-3 akar bercabang yang kecil. Jenis ini memiliki batang yang tegak disetiap ruas dengan 2-7 helai daun.

Secara keseluruhan, E. acoroides dan T. hemprichii adalah jenis yang paling sering dijumpai karena ditemukan di semua stasiun. C. rotundata adalah urutan kedua karena ditemukan di tiga stasiun, sedangkan S. isoetifolium hanya ada di Stasiun 1. Berdasarkan lokasi stasiun penelitian di perairan Ujung Piring pada Stasiun 1 ditemukan 4 spesies lamun, yaitu E. acoroides, T. hemprichii, C. rotundata, dan S. isoetifolium sedangkan E. acoroides, dan T. hemprichii terdapat di Stasiun 3 dan 5. Di Stasiun 2 dan 4 ditemukan 3 species, yaitu E. acoroides, T. hemprichii, dan C. rotundata. Tiga jenis lamun ini ditemukan pada Stasiun 1 dan 2. Berdasarkan waktu pengamatan, pada bulan Juni dan Agustus ditemukan 3 jenis lamun, yaitu $E$. acoroides, T. hemprichii, dan C. rotundata; bulan Juli ditemukan 4 jenis lamun, yaitu $E$. acoroides, T. hemprichii, C. rotundata, dan S. isoetifolium. Vegetasi monospesifik dari T. hemprichii merupakan unit vegetasi yang paling luas sebarannya dan seringkali tumbuh dalam vegetasi campuran pada substrat yang mengalami gangguan. $T$. hemprichii, hidup dalam semua jenis substrat, bervariasi dari pecahan karang hingga substrat lunak, bahkan pada lumpur cair, tetapi akan menjadi dominan hanya pada substrat keras (Den Hartog,

Tabel 1. Variasi komposisi jenis lamun di perairan Ujung Piring, Jepara selama bulan JuniAgustus 2016

\begin{tabular}{ccccccc}
\hline \multirow{2}{*}{ Jenis lamun } & Bulan & \multicolumn{5}{c}{ Stasiun } \\
\cline { 3 - 7 } Enhalus acoroides & & 1 & 2 & 3 & 4 & 5 \\
\hline \multirow{2}{*}{ Thalassia hemprichii } & Juni & + & + & + & - & - \\
& Juli & + & + & + & + & + \\
& Agustus & + & + & + & + & + \\
\hline \multirow{2}{*}{ Cymodocea rotundata } & Juni & + & + & + & + & - \\
& Juli & + & + & + & + & + \\
& Agustus & + & + & - & + & + \\
\hline \multirow{2}{*}{ Syringodium isoetifolium } & Juni & + & + & - & - & - \\
& Juli & + & - & - & + & - \\
& Agustus & + & - & - & - & - \\
\hline & Juni & - & - & - & - & - \\
& Juli & + & - & - & - & - \\
\hline
\end{tabular}




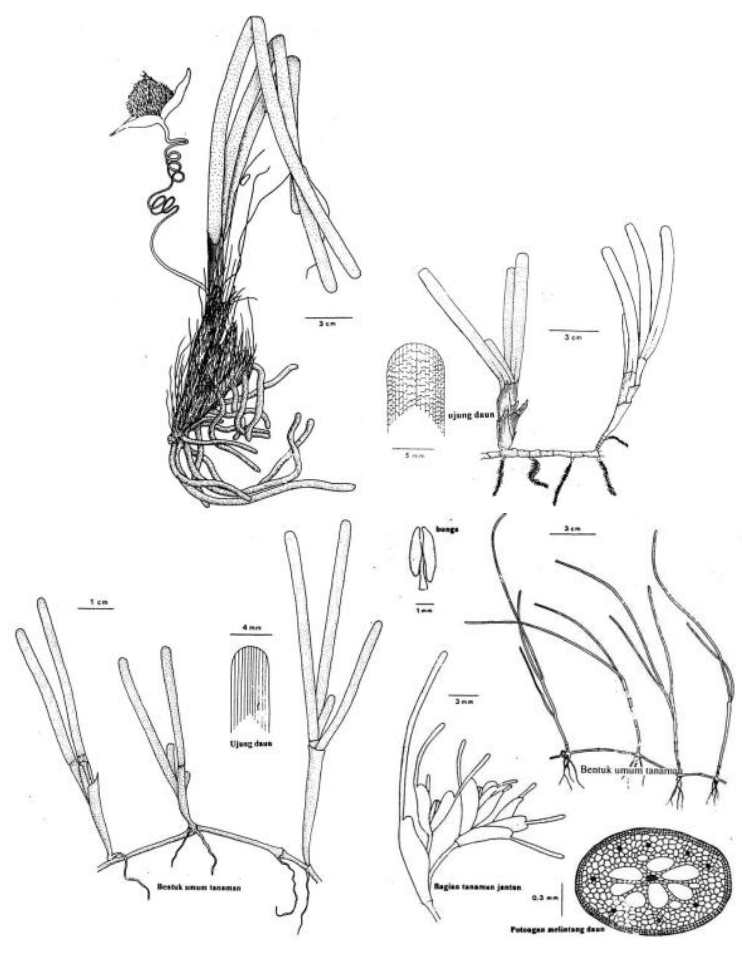

Gambar 2. Jenis lamun yang ditemukan di Perairan Ujung Piring, Jepara (Azkab, 1999)

1970). Asosiasi 2 jenis lamun yang sering terjadi yaitu $E$. acoroides dengan $T$. hemprichii.

Perairan Ujung Piring mempunyai lebih sedikit jenis lamun dibandingankan dengan perairan lain di Indonesia, misalnya Yunitha et al. (2014) menjumpai 6 jenis di pesisir Desa Bahoi, Kabupaten Minahasa Utara, Purnomo et al. (2017) menemukan 7 jenis lamun di Taman Nasional Bali Barat dan terdapat 8 jenis di P. Baranglompo Kep Spermonde (Supriadi et al., 2012). Dibandingkan dengan penelitian di perairan Jepara, Hartati et al. (2017a) di 5 jenis di perairan Bandengan dan 7 jenis di paerairan Teluk Awur (Jepara) dan 6 jenis di Perairan Pulau Karimunjawa (Hartati et al., 2017b).

\section{Kerapatan Lamun}

Pada setiap stasiun pengamatan terdapat kerapatan jenis lamun berbedabeda. Kadang dalam satu kuadran pengamatan terdapat 2-3 jenis lamun yang berasosiasi. Hasil pengamatan kerapatan lamun di perairan Ujung Piring Jepara secara umum paling tinggi adalah 33,87 tegakan T. hemprichii/m² di Stasiun 1 pada bulan Juni dan terendah 4,32 tegakan C. rotundata $/ \mathrm{m}^{2}$ (Tabel 2). Pada bulan Juni menunjukkan kerapatan tertinggi untuk jenis $T$. hemprichii dibandingkan jenis yang lain, juga merupakan kerapatan tertinggi dibandingkan bulan-bulan yang lain.

Bulan Juli T. hemprichii adalah jenis dengan kerapatan tertinggi $(28,55$ tegakan $/ \mathrm{m}^{2}$ ), meskipun jenis ini menurun dibandingkan saat di bulan Juni. E. acoroides adalah jenis dengan kerapatan terendah $\left(5,11\right.$ tegakan $\left./ \mathrm{m}^{2}\right)$. Bulan Agustus E. acoroides adalah jenis dengan kerapatan tertinggi $\left(33,21\right.$ tegakan $\left./ \mathrm{m}^{2}\right)$ jenis ini mengalami kenaikan tertinggi dibandingkan bulan Juni dan Juli, namun pada Stasiun 4 mempunyai kerapatan yang terendah, yaitu 4,89 tegakan $/ \mathrm{m}^{2}$. E. acoroides biasanya tersebar luas terutama pada sedimen halus, tetapi dapat pula tumbuh pada substrat berbatu sedang dan besar. E. acoroides biasanya membentuk vegetasi murni, meskipun demikian spesies ini dapat ditemukan tumbuh dekat dengan spesies lain. E. acoroides hidup di zona intertidal sampai kedalaman $6 \mathrm{~m}$ dan biasanya hidup berdekatan dengan mangrove (Waycott et al., 2004). 
Perbandingan antar jenis lamun menunjukkan bahwa $E$. acoroides dan $T$. hemprichii hampir selalu ada di semua waktu penelitian dan stasiun penelitian. $E$. acoroides dan $T$. hemprichii hanya tidak ditemukan di Stasiun 4 dan 5 pada bulan Juni serta Stasiun 3 pada bulan Juli dan Agustus. T. halasia hemprichii mempunyai distribusi kedalaman yang sempit, mulai daerah eulitoral bawah sampai kedalaman $5 \mathrm{~m}$. T. hemprichii membentuk vegetasi tunggal pada bagian kearah laut (seaward) dari hamparan karang di daerah intertidal yang mendapat tekanan dari gelombang dan kecepatan arus pasut mencapai 2 m/det (Tomascik et. al., 1997). Sedangkan C. rotundata selalu terdapat di Statiun 1, dan hanya ada di Stasiun 2 pada bulan Juni dan stasiun 4 pada bulan Juli. $C$. rotundata, hidup pada daerah dangkal yang tertutup pasir karang, tetapi dapat pula menjadi padat pada daerah berlumpur (Den Hartog, 1970). C. rotundata mempunyai toleransi tinggi pada daerah terbuka (tidak terendam air) dan paling banyak ditemukan pada daerah intertidal dengan terumbu karang yang lebar (Tomascik et. al., 1997).

Jenis lamun yang paling jarang dijumpai adalah $S$. isoetifolium hanya ditemukan pada bulan Juli dengan kepadatan 7,23 tegakan $/ \mathrm{m}^{2}$. S. isoetifolium, utamanya tumbuh pada dasar berlumpur di daerah sublitoral, dapat membentuk suatu padang rumput bawah laut. Menurut
Den Hartog (1970), S. isoetifolium ditemukan pula di daerah intertidal pada daerah dangkal di hamparan terumbu. Jenis ini hanya mampu mentoleransi kekeringan dalam waktu yang sangat singkat.

\section{Penutupan Lamun}

Terdapat variasi penutupan (\%) jenis lamun di perairan Ujung Piring, Jepara selama bulan Juni-Agustus 2016 (Tabel 3). Secara umum penutupan tertinggi dicapai oleh jenis Enhalus acoroides sebesar $48,67 \%$ (Stasiun 2) dan terendah $6,81 \%$ pada $C$. rotundata (Stasiun 4). Variasi bulanan penutupan jenis lamun di perairan Ujung Piring, jepara menunjukkan bahwa pada bulan Juni, presentase penutupan ratarata tertinggi dan terendah terdapat pada T. hemprichii berturut-turut dengan nilai 48,33\% di Stasiun 1 dan $8,71 \%$ di Stasiun 3. Pada bulan Juli, penutupan tertinggi sebanyak 44,38\% E. acoroides di Stasiun 2 dan terendah $6,81 \%$ C. rotundata di Stasiun 4 sedangkan pada bulan Agustus penutupan tertinggi dan terendah ditemukan pada jenis $E$. acoroides sebesar $48,67 \%$ (Stasiun 2) dan $8,87 \%$ (Stasiun 5). Variasi penutupan antar stasiun pengamatan menunjukkan Stasiun 4 mempunyai penutupan lamun yang terendah $(6,81 \%)$ dan Stasiun 2 dengan penutupan lamun tertinggi (48,67\%). Secara umum rata-rata variasi penutupan jenis lamun selama penelitian tersaji pada

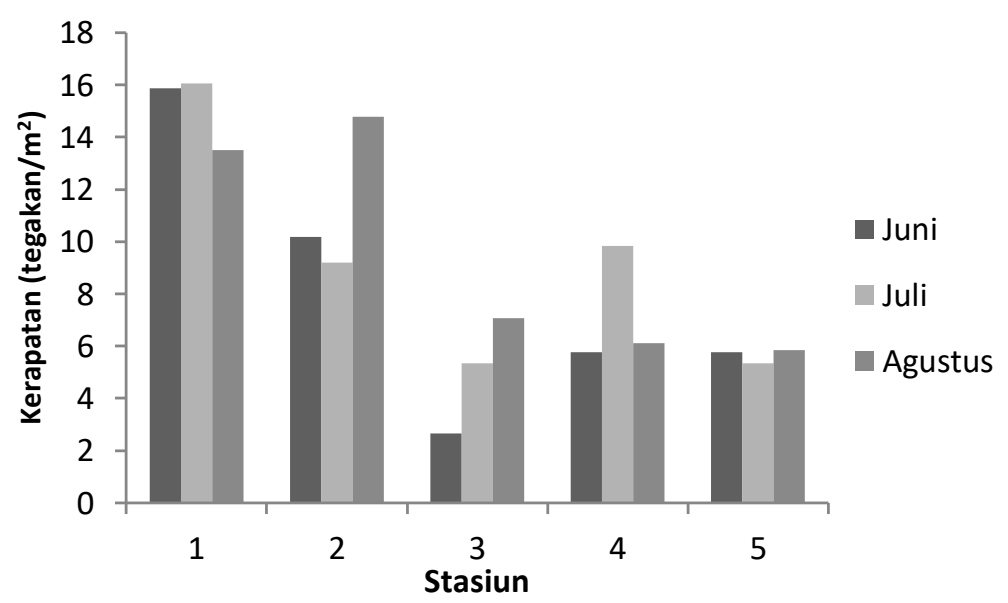

Gambar 3. Variasi rata-rata kerapatan jenis lamun (tegakan $/ \mathrm{m}^{2}$ ) antar stasiun penelitian selama pengamatan di perairan Ujung piring, Jepara. 


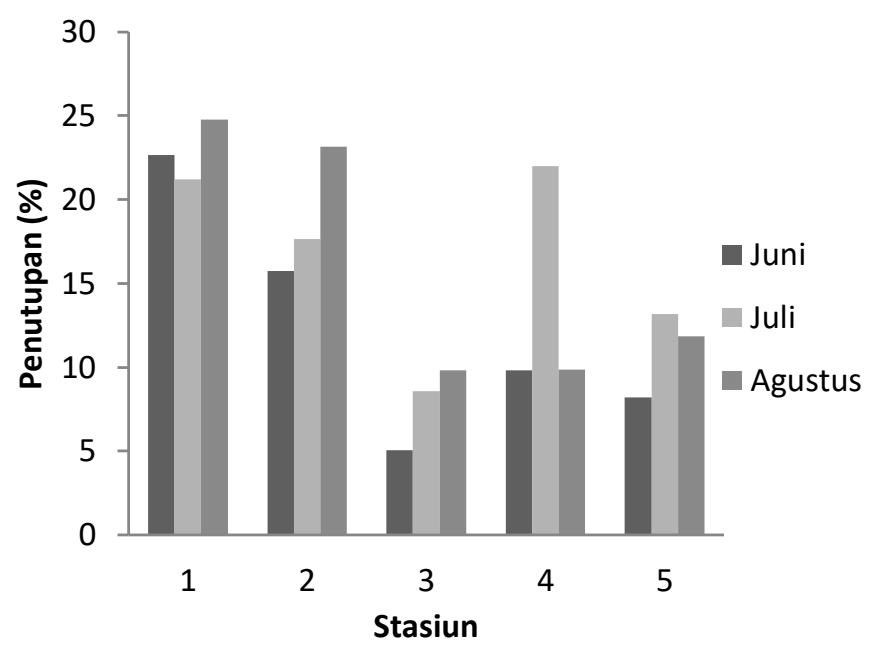

Gambar 4. Variasi rata-rata penutupan jenis lamun antar stasiun penelitian selama pengamatan di perairan Ujung piring, Jepara.

Gambar 4 dibawah ini. Berdasarkan Keputusan MNLH, No. 200/2004, penutupan tersebut termasuk miskin hingga kurang kaya/kurang miskin, karena variasi penutupan berkisar $6,81-48,67 \%$.

E. acoroides merupakan satusatunya spesies yang melepaskan polennya di permukaan air ketika melakukan reproduksi seksual. Hal tersebut membatasi distribusi lamun E. acoroides sehingga hanya terdapat di daerah intertidal dan subtidal (Green dan Short, 2003). Spesies E. acoroides umumnya ditemukan tumbuh pada substrat berlumpur di perairan yang keruh, dapat membentuk spesies tunggal serta dapat mendominasi komunitas padang lamun (Short dan Coles, 2001).

Tipe substrat stabil merupakan indikator kuat tempat tumbuh lamun jenis C. rotundata dan T. hemprichii (Takaendengan dan Azkab, 2010). Kedua spesies tersebut merupakan spesies pionir pada ekosistem padang lamun, spesies ini memiliki kemampuan adaptasi yang sangat baik melalui sistem perakarannya sehingga dapat menyerap nutrisi pada kondisi substrat yang berbeda (Short and Carruthers, 2010).

S. isoetifolium hanya dijunlap pada bulan Juli di Stasiun 1 dengan penutupan 17,3\%. Kondisi lingkungan yang dibutuhkan oleh $S$. isoetifolium adalah perairan yang agak dalam sehingga tidak terpapar dalam jangka waktu yang relatif lama. Kuriandewa (2009) mengemukakan bahwa $S$. isoetifolium dijumpai pada substrat berlumpur sampai pasir dengan kedalaman maksimum 6 meter, tidak dijumpai pada tempat-tempat yang mengalami pemaparan jangka panjang saat surut rendah. Bentuk morfologi daun $S$. isoetifolium tidak memungkinkan air terperangkap diantara daun. Hal ini berbeda dengan lamun yang mempunyai daun tipis dan sering saling melekat dan memerangkap air diantara daun tersebut sehingga bisa tahan terhadap pemaparan yang lebih lama (Tomascik et al., 1997).

Parameter kualitas perairan memegang peranan penting terhadap kelangsungan hidup lamun di perairan. Pengamatan parameter fisika-kimia oseanografi dalam penelitian ini meliputi arus, kedalaman, kecerahan, suhu, $\mathrm{pH}$, dan salinitas tersaji dalam Tabel 12.

Arus di perairan Ujung Piring berkisar 0,080-0,100 m.det-1. Produktivitas padang lamun juga dipengaruhi oleh kecepatan arus perairan. Arus atau pergerakan air dapat membantu suplai unsur hara dan gas-gas terlarut pada tumbuhan lamun. Arus dapat pula menghalau sisa metabolisme dan limbah yang dapat mempengaruhi produktivitas primer dari tumbuhan lamun.

Keberadaan tumbuhan lamun sangat dipengaruhi penetrasi cahaya 
Tabel 4. Parameter Kualitas Perairan Ujung Piring, Jepara selama penelitian

\begin{tabular}{|c|c|c|c|c|c|c|c|}
\hline Waktu & Stasiun & $\begin{array}{c}\text { Arus } \\
\left(\mathrm{m}^{-} \text {det-1) }^{-1}\right)\end{array}$ & $\begin{array}{c}\text { Kedalaman } \\
(\mathrm{cm})\end{array}$ & $\begin{array}{l}\text { Kecerahan } \\
(\mathrm{cm})\end{array}$ & $\begin{array}{l}\text { Suhu } \\
\left({ }^{\circ} \mathrm{C}\right)\end{array}$ & $\mathrm{pH}$ & $\begin{array}{c}\text { Salinitas } \\
(\% \circ)\end{array}$ \\
\hline \multirow{5}{*}{ Juni } & 1 & 0,089 & 115 & 115 & 30 & 7 & 31 \\
\hline & 2 & 0,080 & 112 & 112 & 30 & 7 & 32 \\
\hline & 3 & 0,080 & 105 & 105 & 30 & 7 & 33 \\
\hline & 4 & 0,100 & 120 & 120 & 30 & 7 & 32 \\
\hline & 5 & 0,100 & 110 & 110 & 39 & 7 & 31 \\
\hline \multirow{5}{*}{ Juli } & 1 & 0,082 & 105 & 105 & 28 & 7 & 33 \\
\hline & 2 & 0,089 & 102 & 102 & 29 & 7 & 32 \\
\hline & 3 & 0,093 & 105 & 105 & 29 & 7 & 31 \\
\hline & 4 & 0,100 & 118 & 118 & 29 & 7 & 32 \\
\hline & 5 & 0,095 & 122 & 122 & 29 & 7 & 31 \\
\hline \multirow{5}{*}{ Agustus } & 1 & 0,095 & 112 & 112 & 29 & 7 & 32 \\
\hline & 2 & 0,093 & 114 & 114 & 29 & 7 & 32 \\
\hline & 3 & 0,093 & 108 & 108 & 29 & 7 & 31 \\
\hline & 4 & 0,095 & 116 & 116 & 30 & 7 & 31 \\
\hline & 5 & 0,089 & 124 & 124 & 30 & 7 & 32 \\
\hline
\end{tabular}

matahari, karena cahaya tersebut diperlukan untuk proses fotosintesis. Kecerahan di perairan Ujung Piring pada umumnya sampai dasar (105-124 cm). Lamun membutuhkan intensitas cahaya yang tinggi untuk melaksanakan proses fotosintesis. Produktivitas lamun dibatasi terutama oleh ketersediaan hara dan cahaya (Peterson dan Heck, 1999; Ruiz dan Romero, 2003). Hal ini terbukti dari hasil observasi yang menunjukkan bahwa distribusi padang lamun hanya terbatas pada daerah yang tidak terlalu dalam (Dahuri, 2003). Beberapa aktivitas yang dapat meningkatkan muatan sedimen pada badan air akan berakibat pada tingginya kekeruhan perairan, sehingga berpotensi mengurangi penetrasi cahaya. Hal ini dapat menimbulkan gangguan terhadap produktivitas primer ekosistem padang lamun.

Penetrasi cahaya atau kecerahan akan berhubungan dengan suhu perairan. Suhu di perairan Ujung piring $28-30^{\circ} \mathrm{C}$. Beberapa peneliti melaporkan adanya pengaruh nyata perubahan suhu terhadap kehidupan lamun, antara lain dapat mempengaruhi metabolisme, penyerapan unsur hara dan kelangsungan hidup lamun. Walaupun padang lamun secara geografis tersebar luas yang diindikasikan oleh adanya kisaran toleransi yang luas terhadap temperatur, pada kenyataannya spesies lamun di daerah tropik mempunyai toleransi yang rendah terhadap perubahan temperatur. Kisaran suhu optimal bagi spesies lamun adalah 28$30^{\circ} \mathrm{C}$. Kemampuan proses fotosintesis akan menurun dengan tajam apabila temperatur perairan berada di luar kisaran optimal tersebut (Dahuri, 2003).

$\begin{aligned} & \text { Salinitas dapat berpengaruh } \text { biomassa, } \\ & \text { terhadap produktivitas, }\end{aligned}$ kerapatan, lebar daun dan kecepatan pulih lamun. Sedangkan kerapatan semakin meningkat dengan meningkatnya salinitas, namun jumlah cabang dan lebar daun semakin menurun (Azkab, 1999). Kisaran salinitas di perairan Ujung Piring adalah 31-32\%. Toleransi lamun terhadap salinitas bervariasi antar jenis dan umur (Lirman and Cropper, 2003). Spesies lamun memilki kemampuan toleransi yang berbeda-beda terhadap salinitas, namun sebagian besar memilki kisaran yang lebar yaitu antara 10 dan $40 \%$. Nilai salinitas optimum untuk spesies lamun adalah 35 $\%$. Salah satu faktor yang menyebabkan kerusakan ekosistem padang lamun adalah meningkatnya salinitas yang diakibatkan oleh berkurangnya suplai air tawar dari sungai (Fourqurean and Robblee, 1999). Hartati et al. (2012) menyatakan salinitas berpengaruh 
terhadap kerapatan dan biomassa lamun. Lamun yang hidup di daerah estuari cenderung lebih toleran terhadap perubahan salinitas. Namun respon Iamun terhadap salinitas tidak secara spontan namun lebih ke waktu yang lebih lama (Zeeman et al., 1999)

Hasil pengukuran data ukuran butir pada semua stasiun didominasi oleh substrat dasar perairan berupa pasir berkisar 59,73-85,76\%. Sedangkan substrat dasar perairan yang berupa kerikil berkisar 2,18-11,5\% dan berupa lumpur berkisar antara 12,06-36,04 (\%). Padang lamun hidup pada berbagai macam tipe substrat, mulai dari lumpur sampai sedimen dasar yang terdiri dari endapan lumpur halus sebesar $40 \%$. Kedalaman substrat berperan dalam menjaga stabilitas sedimen, sebagai pelindung tanaman dari arus air laut, dan tempat pengolahan serta pemasok nutrient. Keberadaan substrat sangat penting bagi lamun,sebagai tempat hidup dan pemasok nutrisi. Berdasarkan Kiswara (1997) padang lamun di Indonesia dikelompokkan dalam enam kategoriberdasarkan tipe substratnya, yaitu lamun yang hidup pada substrat lumpur, lumpur pasiran, pasir, pasir lumpuran, puing karang, dan batu karang.

\section{KESIMPULAN}

Selama periode penelitian ditemukan 4 jenis Lamun yaitu Enhalus acoroides, Thalasia hemprichii, Cymodocea rotundata, dan Syringodium isoetifolium. Kerapatan tertinggi dan terendah ditemukan pada Thalassia hemprichii, yaitu 33,87 dan 4,35 tegakan $/ \mathrm{m}^{2}$. Persentase penutupan tertinggi ditemukan pada Enhalus acoroides dengan nilai $48,67 \%$ dan yang terendah $8,71 \%$ oleh $T$. hemprichii. Terdapat variasi komposisi dan kerapatan berdasarkan waktu pengamatan, hal ini menunjukkan adanya pengaruh lingkungan dan tidak terjadi persebaran lamun yang merata pada daerah tersebut.

\section{DAFTAR PUSTAKA}

Azkab, MH. 1999. Pedoman Inventarisasi Lamun. Oseana, XXIV(1): 1- 16
Dahuri, R. 2003. Keanekaragaman hayati laut: aset pembangunan berkelanjutan Indonesia. Gramedia Pustaka Utama. Jakarta

Den Hartog, C. 1970. The seagrasses of the world. North Holland Publ. Co. Amsterdam: 275 pp.

Duarte, C.M. 2002. The future of the seagrass meadows. Environ. Conser. 29:192-206.

El Shaffai, A. 2011 . Field guide to seagrasses of the Red Sea. 1st ed. Gland, Switzerland: IUCN and Courbevoie, France.

English, S., Wilkinson, C. \& Baker, V. 1994. Survey Manual for Tropical Marine Resources. Published on behalf of the ASEAN-Australia Marine Science. Townswile: $367 \mathrm{pp}$.

Fourqurean, J.W. \& Robblee, M.B. 1999. Florida Bay: A brief history of recent ecological changes. Estuaries 22:345357.

Green, E.P. \& Short, F.T. 2003. World Atlas of Seagrass. Prepared by the UNEP World Conservation Monitoring Centre University of CaliforniaPress. Berkeley: USA.

Hartati, R., Djunaedi, A. \& Haryadi. 2012. Struktur komunitas padang lamun di Perairan Pulau Kumbang, Kepulauan Karimunjawa. Ilmu Kelautan. 17(4): 217225

Hartati, R., Trianto, A. \& Widianingsih. 2017a. Habitat characteristic of two selected locations for sea cucumber ranching purposes. IOP Conference Series: Earth Environ. Sci.55(1),012041

Hartati, R., Widianingsih, Trianto, A., Zainuri, A., Ambariyanto. 2017b. The abundance of prospective natural food for sea cucumber Holothuria atra at Karimunjawa Island waters, Jepara, Indonesia. BIODIVERSITAS. 18(3):947953. DOI: 10.13057/biodiv/d180311.

Hogarth, P. 2007. The Biology of Mangroves and Seagrasses, 2nd edition. Oxford University Press. New York. 273 pp.

Kementerian Lingkungan Hidup. 2004. Keputusan Menteri Negara Lingkungan Hidup Nomor 200 Tahun 2004 tentang Kriteria Baku Kerusakan dan Pedoman Penentuan Status Padang Lamun. Jakarta: Kementerian Lingkungan Hidup. $16 \mathrm{hlm}$. 
Kiswara, W. 1997. Struktur Komunitas Padang Lamun Perairan Indonesia. Inventarisasi dan Evaluasi Potensi LautPesisir II, Jakarta (ID): P3O LIPI.

Kuriandewa, T.E. 2009. Tinjauan tentang lamun di Indonesia. Lokakarya Nasional I Pengelolaan Ekosistem Lamun: Peran Ekosistem Lamun dalam Produktivitas Hayati dan Meregulasi Perubahan Iklim. Jakarta, 18 November 2009.

Lirman, D. \& Cropper, W.P. 2003. The Influence of Salinity on Seagrass Growth, Survivorship, and Distribution within Biscayne Bay, Florida: Field, Experimental, and Modeling Studies. Estuaries 26(1): 131-141

Peterson, BJ., \& Heck, K.L.Jr. 1999. The potential for suspension feeding bivalves to increase seagrass productivity. J. Exp. Mar. Biol. Ecol. 240(1): 37-52

Purnomo, X.K., Yusniawati, Y., Putrika, A., Handayani, W. \& Yasman. 2017. Keanekaragaman spesies lamun pada beberapa ekosistem padang lamun di kawasan Taman Nasional Bali Barat. Sem. Nas. Masy. Biodiv. Indon. 3:236240.

Ruiz, J.M. \& Romero, J. 2003. Effects of distrubances caused by coastal construction on spatial structure, growth dynamics and photosynthesis of the seagrass Posidonia oceanica. Mar. Pollut. Bull. 46(12): 1523-1533

Seddon, S., Connolly, R.M. \& Edyvane, K.S. 2000. Large-scale seagrass dieback in Northern Spencer Gulf, South Australia. Aquatic. Bot. 6: 297-310.

Short, F.T. \& Carruthers, T.J.R. 2010. Halophila ovalis. The IUCN Red List of Threatened Species 2010: e.T169015A6561794. http://dx.doi.org/10.2305/IUCN.UK.201 0-Short 3.RLTS.T169015A6561794.en.
Short, F.T. \& Coles, R.G. 2001. Global seagrass research methods. Elsevier, Amsterdam.

Sudjana. 1996. Metode Statistik. Bandung: Tarsito Press. $508 \mathrm{hlm}$.

Supriadi, Kaswadji, R.F., Bengen, D.G. \& Hutomo, M. 2012. Komunitas Lamun di Pulau Barranglompo Makassar: Kondisi dan Karakteristik Habitat. Maspari J. 4(2):148-158.

Suryabrata, S. 1992. Metoda Penelitian. Rajawali Press, Jakarta

Takaendengan, K., \& Azkab, M.H. 2010. Struktur komunitas lamun di Pulau Talise, Sulawesi Utara. Oseanol. Limnol. 36(1):85-95.

Thangaradjon, T., Sridhar, R., Senthilkumar, S. \& Kanamnau, S. 2007. Seagrass resources assessment in the Mandaparn Coast of the Gulf of Mannar Biosphere reserve, India. Applied Ecol. Environ. Res. 6(1):139-146.

Tomascik, T., Mah, A.J., Nontji, A. \& Moosa, M.K. 1997. The Ecology of the Indonesian Seas. Part II. (Chapter 18: Seagrass). Dalhousie Univ. 829-906pp

Waycott, M., McMahon, K., Mellors, J., Calladine, A. \& Kleine, D. 2004. A Guide to Tropical Seagrasses of the Indo-West Pacific. James Cook University, Townsville (AU).

Yunitha, A., Wardiatno, Y., \& Yulianda, F. 2014. Diameter Substrat dan Jenis Lamun di Pesisir Bahoi Minahasa Utara: Sebuah Analisis Korelasi. J.llmu Pertanian Indonesia. 19(3): 130-135

Zeeman, J., Fourqurean, J.W., \& Frankovich, T.A. 1999. Seagrass Die-off in Florida Bay: Long-term Trends and Growth of Turtle Grass, Thalassia testudinum. Estuaries 22(2B):460-470 